Journal of Advanced Research in Fluid Mechanics and Thermal Sciences

Journal homepage: www.akademiabaru.com/arfmts.html ISSN: $2289-7879$

\title{
Intelligent Control Based Estimation of Heat Transfer Coefficient from Four Flat Tubes with Different Attack Air Angles
}

\author{
Muhammad Asmail Eleiwi ${ }^{1,}{ }^{*}$, Tahseen Ahmad Tahseen ${ }^{2}$, Ahmed Hasan Ghareeb $^{3}$ \\ Department of Mechanical Engineering, College of Engineering, Tikrit University, Tikrit, Iraq \\ Department of Mechanical Engineering, College of Engineering, University of Kirkuk, Kirkuk, Iraq \\ 3 Department of Petroleum Engineering, College of Engineering, University of Kirkuk, Kirkuk, Iraq
}

\section{ARTICLE INFO}

\section{Article history:}

Received 15 December 2019

Received in revised form 17 April 2020

Accepted 21 April 2020

Available online 30 June 2020

Keywords:

ANN modeling; data driven; different attack air angle; flat tube

\section{ABSTRACT}

The inlet air flow over surface of heat exchanger in many cases for the direction is not orthogonal. To study of the heat transfer with change of air inlet angles, the paper presents how to predict the heat transfer coefficient for four flat tubes in a crossflow of air using an artificial neural networks (ANNs). The experimental setup with inclined the air incoming flow direction, the heat transfer coefficient of three air inlet angles $\left(90^{\circ}, 45^{\circ}\right.$ and $\left.30^{\circ}\right)$ are studied separately for five inlet air velocity $0.2,0.5,0.6,0.8$, and $1.2 \mathrm{~m} / \mathrm{s}$ to corresponding the Reynolds number (Re), based on the transverse diameter are $1668,2006,2471,2658$, and 3782 . The three cases of heat flux on the all tubes surface $13.2,38.5$, and $99.8 \mathrm{~W} / \mathrm{m} 2$. The predicted results for heat transfer coefficient show a good agreement with experimental data. The accuracy between ANNs approach model and actual values (experimental) obtained with a mean relative error less than $2.2 \%$, and the coefficient of determination $\left(R^{2}\right)$ around $99.8 \%$.

\section{Introduction}

The many industrial applications require the use of heat exchangers with configurations of tubes, finned or un-finned, represent as heat exchangers in refrigeration, air conditioning, heaters, radiators, etc. This equipment should be dimensioned in accordance to the availability of space in the plan (project) that are section usually having to be compact in size and lightweight to take these confined spaces. The air inlet flow direction is not orthogonal to the heat exchanger surface in many cases [1]. It has been of attentiveness to several researchers to investigate the heat transfer and fluid flow over objects with different shapes. Flat tubes have not been investigated to the same magnitude; therewith they play a significant role in several technical applications such as automobile

\footnotetext{
* Corresponding author.

E-mail address: muham76@tu.edu.iq 
radiators and trendy heat exchangers. The design of flat tubes has been recently inserted to be used in car air conditioning condensers and evaporators. The latest developments in automobile welded aluminum industrialization technology have made the cost of the heat exchanger with flat tube construction more convenient [2]. Heat exchangers with flat tube expected to have minimized pressure drop of air side and best air side coefficients of heat transfer compared to circular shape heat exchangers. It is expected the pressure drop less than that for circular shape due a smaller wake region. Also, the same reason noise and vibration is expected to be lower than in flat tube heat exchangers compared with heat exchangers circular shape. The tube heat exchangers are used in a great many chemical reaction systems and energy conversion for instance nuclear reactors to refinery condensers. More importantly design parameter of tube heat exchangers are the external coefficient of heat transfer of the tube and the pressure drop of the external fluid flow. According to previously published studies in the literature, the influence the shape of the tube and configuration have specific they can have a positive impact on heat transfer [3-5]. Rocha et al., [6] expanded a mathematical model for hybrid configurations of circular and elliptical tubes finned conservation of energy and heat transfer coefficients acquired experimentally using the technique of sublimation of naphthalene and part of similarity with the transfer of heat and mass.

Wang et al., [7] have two methods of numerical studied heat transfer over finned flat tubes with uniform tube wall temperature. The results show that obtained by applying a uniform temperature thermal boundary condition on the fin surfaces has only slightly differences with the results obtained by the associated numerical method. Otherwise, the maximum mean Nusselt number is the withoutuniformity temperature on the of wall fin and on the tube wall. Experimental study was carried out for investigating pressure drop and heat transfer characteristics of toothed finned tube banks with staggered configuration. The results display a variety of fin density effects, the spacing between the tube transversal pitch and longitudinal pitch. For fin height is constant, led to an increase in the density of fin in an increase in the Euler number, also, the observed decrease gradually in the Nusselt number with increase Reynolds number [8]. The heat transfer and pressure investigation experimental both in-line and staggered flat tube configuration by Ishak et al., [9] and Jassim et al., [10]. Tahseen et al., [11] have 2D numerical studies incompressible, steady state flow and using the body fitted coordinate (BFC). The first study heat transfer over a two flat tube staggered and second study the heat transfer over series in-line flat tube between parallel plate channel. The two studies show effects of the Reynolds number on the heat transfer coefficient. The results revealed that the heat transfer coefficient increase with an increase of Reynolds number always the results confirm with Brajesh and Sandipan [12].

Artificial neural networks (ANNs) in many engineering applications have been used because of providing good and more reasonable solutions $[13,14]$. A feed-forward back-propagation ANN using by Ermis et al., [15] to analyse the heat transfer rate of phase change process in an around the finned tube, both numerical and experimental has investigated. The relative error less than $5.58 \%$ at the experimental while numerical model ends around 14.99\%. Fadare and Fatona [16] have studied ANNs model of a multi-row with staggered arrangement, multi column in cross-flow, tube to tube heat exchanger and the experimental data. The results show that the average absolute relative error around $1 \%$ and $4 \%$ for the training and testing data sets, respectively. Islamoglu and Kurt [17] used the ANNs model for predicted the rate of heat transfer in corrugated channel. The error between the ANNs approach and experimental data the approximation of the mean absolute relative error is less than 4\%. Tahseen et al., [18] carried out analyzed numerically the heat transfer and fluid flow characteristics of air flow in an in-line flat tube bundle configuration. They used the neuro-fuzzy inference system (ANFAS) model to predict values of thermofluids coefficient. The results show that 
the average deviation between the numerical and ANFIS model values for average Nusselt number and dimensionless pressure drop are $1.9 \%$, and $2.97 \%$, respectively.

This paper focused on the capability of ANN for heat transfer analysis in laminar forced convection heat transfer across four flat tube bundles with different attack angles as well as change in the heat flux. The supervised data-driven ANN model is applied to predict the outcomes of new independent input data. Furthermore, to discover and learn patterns correlated between input data sets and the target values.

\section{Experimental Setup}

This work was carried out in the heat transfer laboratory. The experimental setup consists of an open circuit wind tunnel, a variable electric power supply, cartridge heater, Aluminum flat tubes, Ttype of thermocouple, multi-channel temperature meter, hot wire anemometer, and volt and current measurement. The Figure 1 shows the experimental setup. The TecQuipment (TQ) cross flow heat exchanger is open circuit wind tunnel consists of four sections which are shown respectively: the stagnation, extended, test and end region. The extended region with length $1290 \mathrm{~mm}$ was placed before the test section to let the full developed of the flow before arriving the tube arrangement. At the entrance of the extended region, were arranged metal screen, that is intended to regulate the flow before entering the test section. The wind tunnel consists of an exhaust fan with direct drive by electric motor. The TQ wind tunnel operation range between 220 VAC to 240 VAC, with 5.25 A single phase, and $50 \mathrm{~Hz}$ frequency.

After finishing the installation of all materials and equipment show in Figure 2, measurements done on the essential parts of TQ (i.e., speed of air flow, pressure drop on the test rig and temperature for all points, respectively). To measure the variation of temperature by forced convection at the test rig, fourteen thermocouples placed in each test rig. All of the thermocouples were placed in the middle between the side walls of the wind tunnel and on the midline of the elemental channels. Two thermocouples were placed at the arrangement inlet $\left(T_{\mathrm{in}, 1}, T_{\mathrm{in}, 2}\right)$, Three at surfaces of tubes $\left(T_{\mathrm{s}, 1}-T_{\mathrm{in}, 3}\right)$, and three at outlet air flow $\left(T_{\mathrm{out}, 1}-T_{\text {out }, 3}\right)$ in one elemental channel. An additional thermocouple ( $T_{\text {bef }}$ ) was placed on the extended region at $150 \mathrm{~mm}$ before the test module to measure the temperature of free stream as shown in Figure 2.

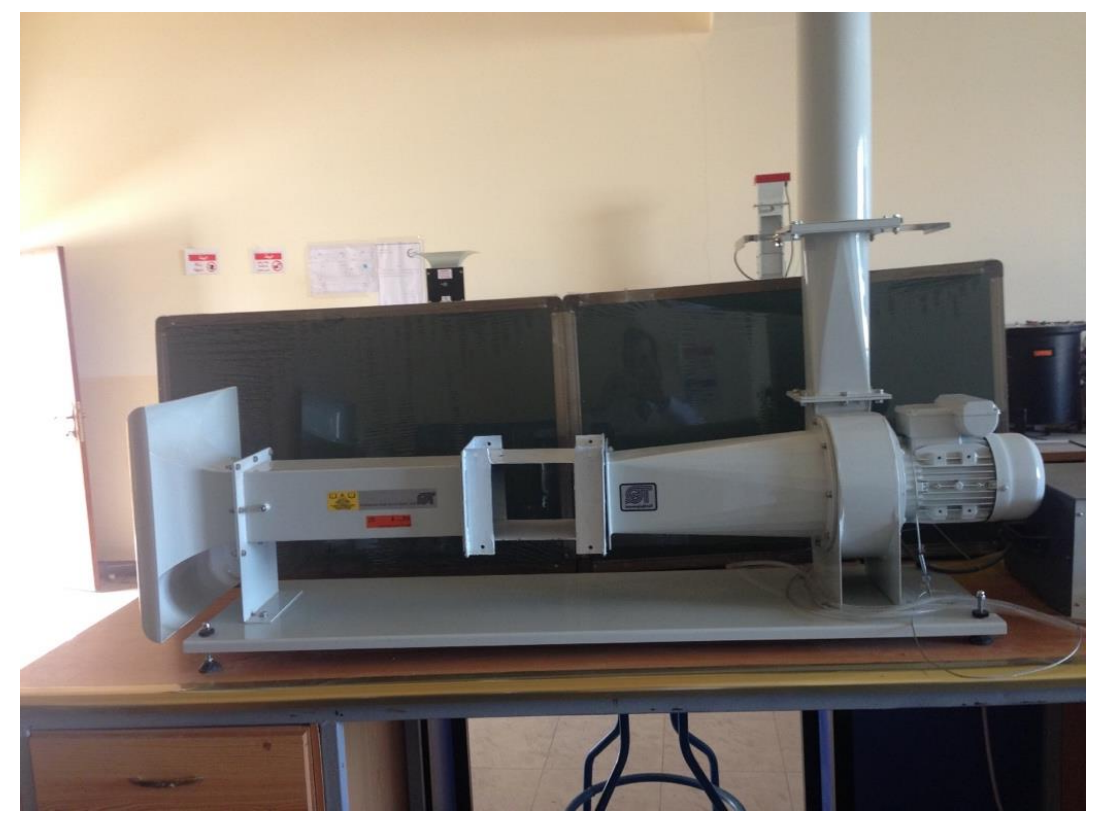

Fig. 1. The TQ wind tunnel that is used in the experimental testing 


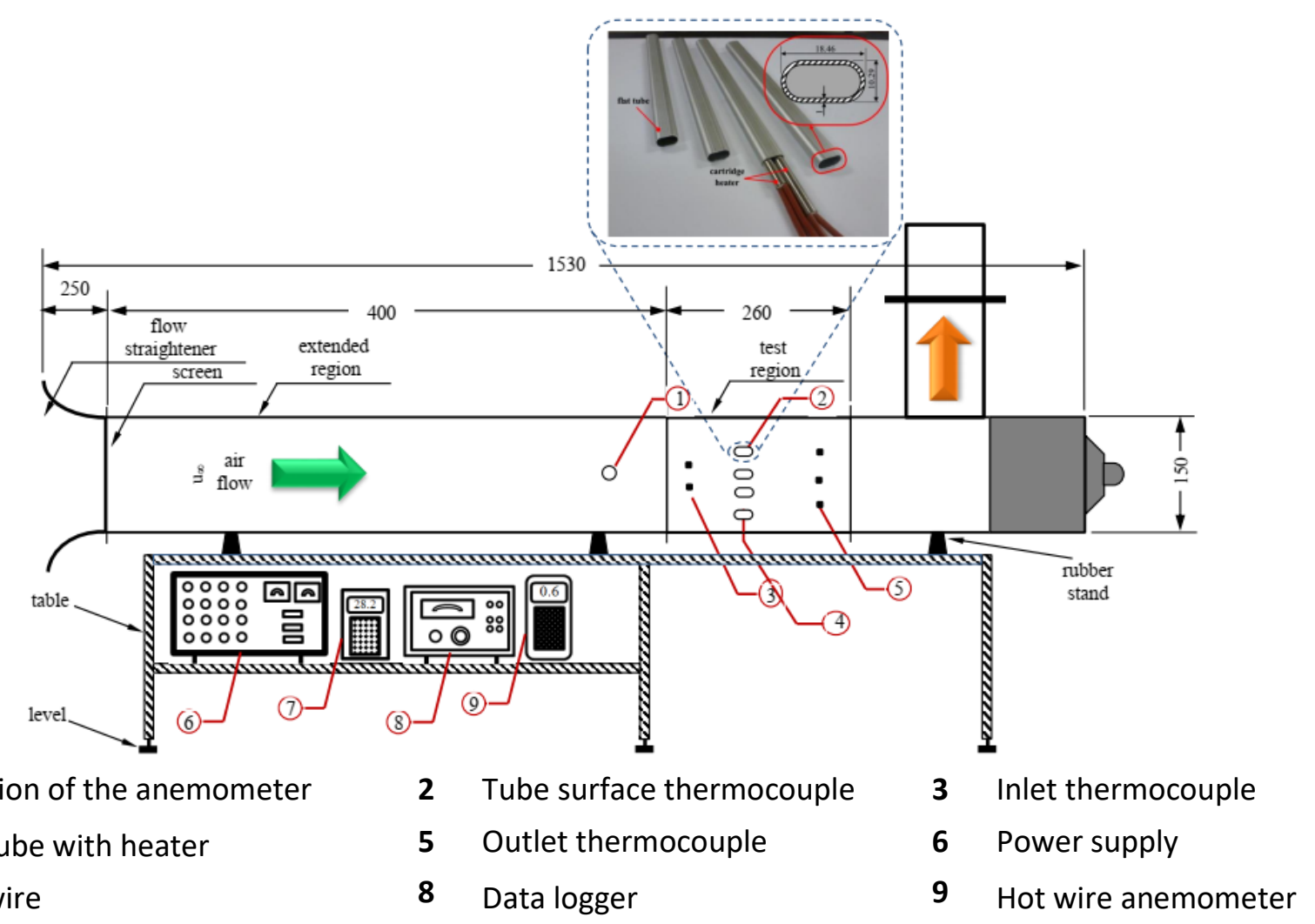

Fig. 2. The schematic displayed of the experimental approach, all dimensions ( $\mathrm{mm})$

Thermocouples in the surfaces of tubes showed that the difference between the tubes in one element channel is negligible and the others are within $\pm 0.53^{\circ} \mathrm{C}$ margin with respect to average of the four thermocouples. Finally, the thermocouples placed in the extended region for purpose of measuring the free stream temperatures within $\pm 0.22^{\circ} \mathrm{C}$ margin with respect to the average temperature measured inlet arrangement, in all the tests carried out in this work.

\subsection{Construction Module of Wood}

The experimental work includes a several units from the wood with different angles of air attack. The wood is $25 \mathrm{~mm}$ thickness. The construction of a wood in the specific dimensions the drilling holes for tubes installation positions and according to the required geometry and arranging sections to measure components shown in Figure 3. The pass the assembly later in the heat exchanger (flat tubes) and the results of next fixation the wood module, through the flat tube holes determined by the arrangement geometry. The all configurations had one row of with flat tubes at the air flow externally. Four flat tubes were inserting on each wood module in accordance with last design as shown in Figure 3(c). The shape and configuration of the tube is shown in Figure 4. 


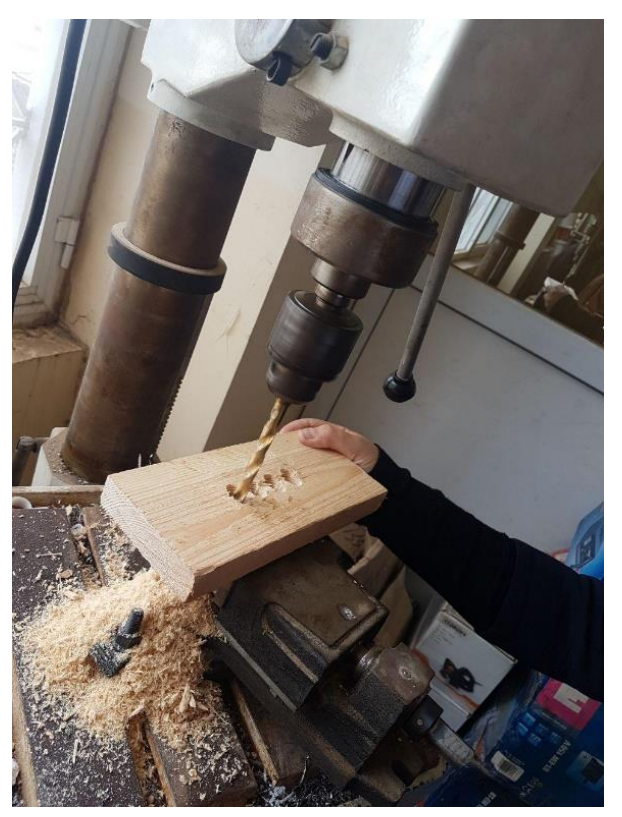

(a)

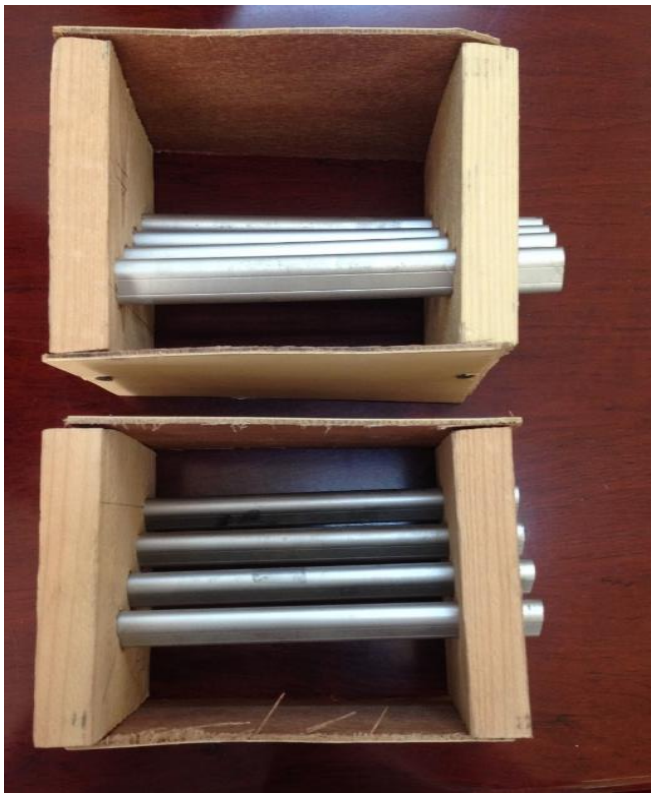

(b)

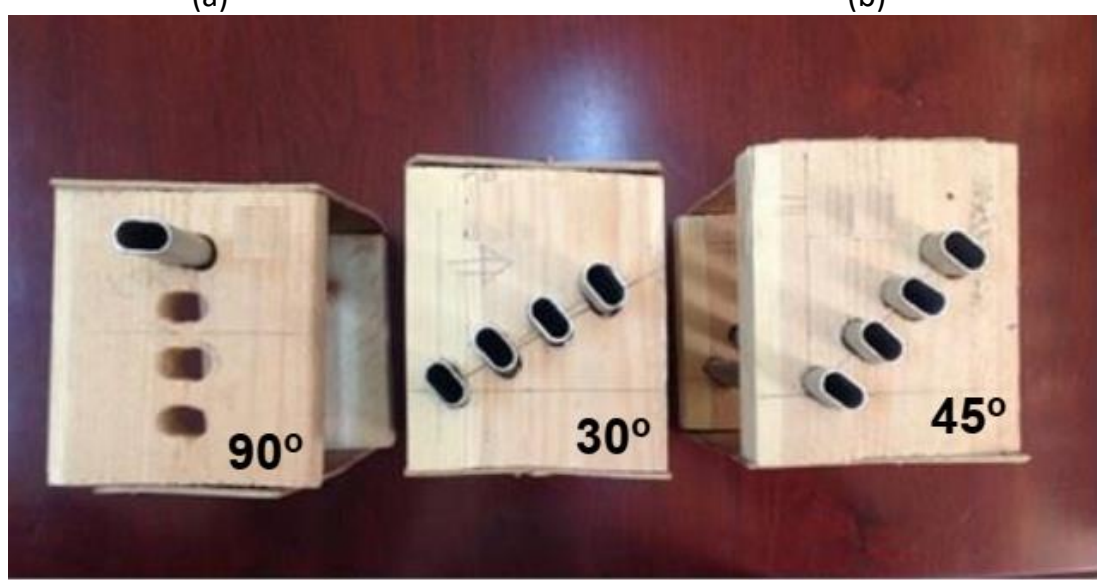

(c)

Fig. 3. The wood module flat tube, (a) Drilling tube locations, (b) Top view of test rig, (c) Three wood models

Started each run by selecting the voltage and current for the cartridge heaters and air velocity of free stream, then we waited for (1.5-2.0) hour while monitor the changes in voltage, current, $T_{\text {bef, }}$ $T_{\mathrm{in}, 1}, T_{\mathrm{in}, 2}, T_{\mathrm{s}, 1}-T_{\mathrm{s}, 3}$ and $T_{\mathrm{out}, 1}-T_{\mathrm{out}, 3}$. We had taken final readings when the relative changes in the voltage, current and temperature were less than (0.5-0.8), (0.03-0.09) and (0.044-0.075)\%, respectively. These changes were estimated relative by repeating the same value $R e_{\mathrm{Dh}}$ value, between (4-6) hours. It should be noted that these relative changes are small when compared with the uncertainties in the relevant measurements. 

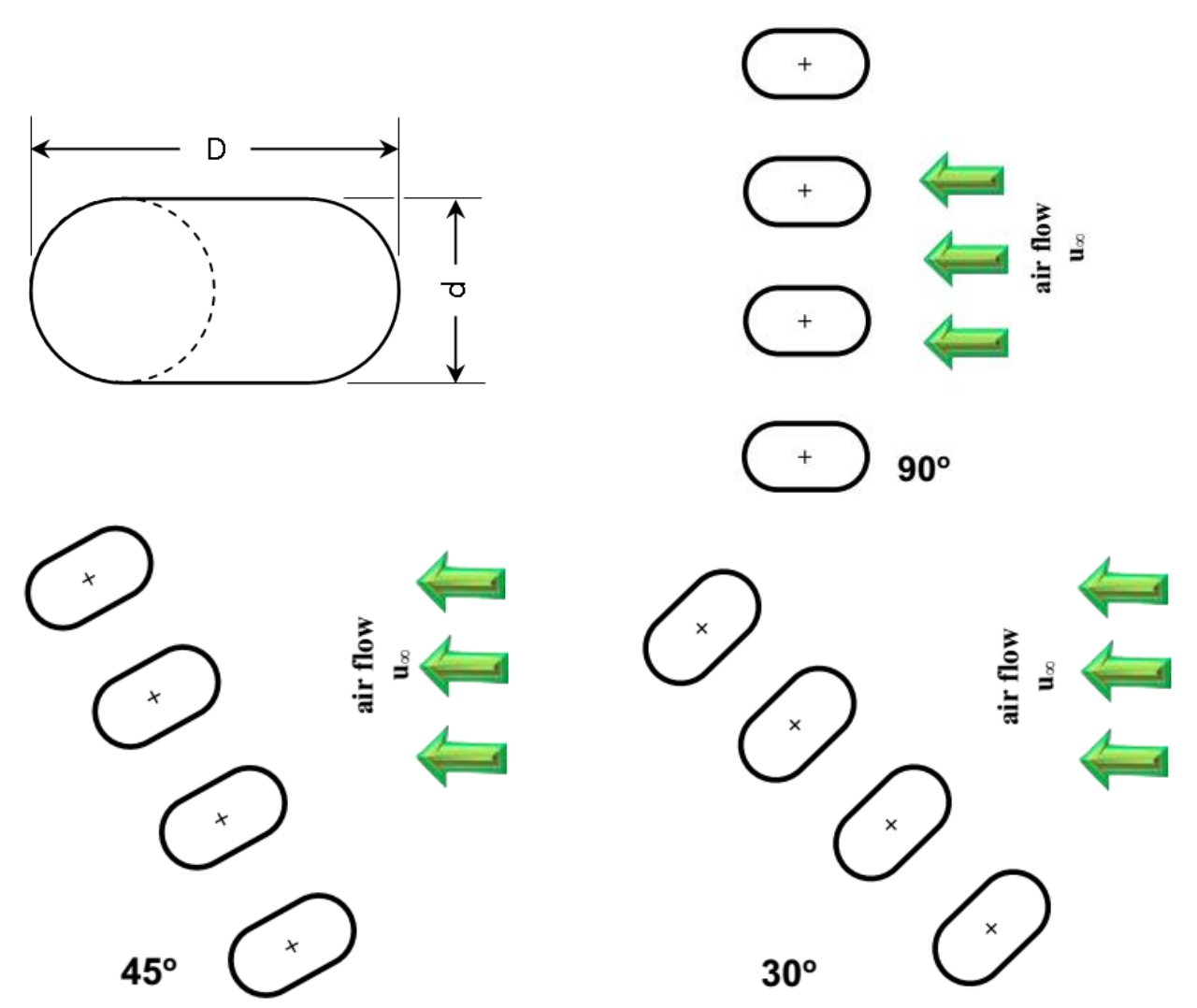

Fig. 4. Cross section of test core of tube row

\section{Data Collection}

This experiment involves laminar external airflow. The following relations for the relevant air properties are used in the following calculations. They are based on data and valid in the range temperature of $275 \mathrm{~K} \leq 0.5\left(\overline{T_{\text {ln }}}+\overline{T_{\text {out }}}\right) \leq 375 \mathrm{~K}[19]$ :

$$
\left.\begin{array}{ll}
\rho_{a}=2.209-3.414 \times 10^{-3}\left(\frac{\overline{T_{\mathrm{in}}}+\overline{T_{\text {out }}}}{2}\right), & \mathrm{kg} / \mathrm{m}^{3} \\
c_{P a}=\left[9.848+6.76 \times 10^{-4}\left(\frac{\overline{T_{\mathrm{In}}}+\overline{T_{\text {out }}}}{2}\right)\right] \times 10^{2}, & \mathrm{~J} /(\mathrm{kg} \mathrm{K}) \\
k_{a}=\left[3.479+7.58 \times 10^{-2}\left(\frac{\overline{T_{\mathrm{in}}}+\overline{\overline{T_{\text {out }}}}}{2}\right)\right] \times 10^{-3}, & \mathrm{~W} /(\mathrm{m} \mathrm{K}) \\
\mu_{a}=\left[4.475+4.564 \times 10^{-2}\left(\frac{\overline{T_{\mathrm{In}}}+\overline{\overline{T_{\text {out }}}}}{2}\right)\right] \times 10^{-6}, & \mathrm{~kg} /(\mathrm{m} \mathrm{s})
\end{array}\right\}
$$

where $\overline{T_{\mathrm{in}}}=\frac{1}{n} \sum_{i=1}^{n}\left(T_{\mathrm{in}}\right)_{\mathrm{i}}, \quad n=2, \overline{T_{\text {out }}}=\frac{1}{n} \sum_{i=1}^{n}\left(T_{\text {out }}\right)_{\mathrm{i}}, \quad n=3$

The electrical heat gain rate [voltage $(E) \times$ current $(\mathrm{I})$ ] and uniform heat flux (UHF) from the outer tube surface can be evaluated as:

$$
q_{\text {in }}=E \times I
$$

The steady state heat balance of the electrical heat test surface can be written as:

$$
q_{\text {convection }}=q_{\text {in }}-q_{\text {conduction }}-q_{\text {radiation }}
$$


Heat transfer from the system is; Conduction between laboratory and the wall of the tubes was neglected because of the extremely low thermal conductivity of air $\left(0.23 \mathrm{~W} / \mathrm{m}^{\circ} \mathrm{C}\right)$ and Teflon, negligible temperature difference between the laboratory and Teflon outer walls.

Radiation heat transfer between the surfaces of the tubes and the surrounding were also neglected. Based on the measurement of $0.5\left(\overline{T_{l n}}+\overline{T_{\text {out }}}\right)$ and $\overline{T S}$, the radiation heat transfer coefficient was estimated as [20]:

$\overline{h_{\text {rad }}}=\varepsilon \times \sigma \times\left[\left\{\left(\frac{\overline{T_{\mathrm{n}}}+\overline{T_{\text {out }}}}{2}\right)^{2}+\left(\overline{T_{\mathrm{s}}}\right)^{2}\right\} \times\left\{\left(\frac{\overline{T_{\mathrm{n}}}+\overline{T_{\text {out }}}}{2}\right)+\overline{T_{\mathrm{s}}}\right\}\right]$

where $\overline{T_{\mathrm{s}}}=\frac{1}{n} \sum_{i=1}^{n}\left(T_{\mathrm{s}}\right)_{\mathrm{i}}, \quad n=3$

For a commercial aluminium tube with emissivity, $\varepsilon \cong 0.028$ [21], $h_{\text {rad }}$ was found in a range of $(0.174-0.205) \mathrm{W} /\left(\mathrm{m}^{2}{ }^{\circ} \mathrm{C}\right)$ with the convection heat transfer coefficient, $h$, approximately between $0.01 \%$ and $0.15 \%$. Thus, the heat transfer between the air and the surface of the tubes was actually due to the convection, and the mechanism of the Eq. (3) was rewritten as [22]:

$q_{\text {convection }} \cong q_{\text {sup }}=\bar{h} A_{\mathrm{s}}\left[\overline{T_{\mathrm{s}}}-\left(\frac{\overline{T_{\mathrm{In}}}+\overline{T_{\text {out }}}}{2}\right)\right]$

where $A_{\mathrm{s}}=n \times[\pi d+2(D-d)] \times L$

where $\overline{T_{l n}}$ the inlet air temperature was the various between $17.1^{\circ} \mathrm{C}$ to $24.8^{\circ} \mathrm{C}$ and $\overline{T_{S}}$ the average temperature of tubes surface. For the steady state condition, the overall heat transfer rate, $q_{\text {convection }}$ was equal to the electrical heat supply, qin. From Eq. (3), the overall heat transfer coefficient was determined as:

$\bar{h}=\frac{q_{\text {sup }}}{A_{\mathrm{s}}\left[\overline{T_{\mathrm{s}}}-\left(\frac{\overline{T_{1 \mathrm{n}}}+\overline{T_{\text {out }}}}{2}\right)\right]}$

and it is usually used in the overall Nusselt number, which is defined as:

$N u=D_{h} \times \frac{h}{k_{\mathrm{f}}}$

where $k_{\mathrm{f}}$, is the thermal conductivity of air.

It can be used with the hydraulic diameter of the flat tube:

$D_{\mathrm{h}}=4 \times \frac{\left[\frac{\pi}{4}(d)^{2}+(D-d) d\right]}{\pi d+2(D-d)}$

The Reynolds number based transverse diameter of flattened tube is defined as:

$R e_{d}=u_{\max } \times d \times \frac{\rho_{\mathrm{f}}}{\mu_{\mathrm{f}}}$ 
where $u_{\max }=S_{T} \cdot u_{\infty} /\left(S_{T}-d\right)$

$S_{T}$ is the distance between centre of two tubes.

$u_{\infty}$ is the air free stream velocity.

The calculation of Colburn $j$-factor is presented by the following non-dimensional parameter:

$j=\frac{N u}{\operatorname{Re} \times P r^{1 / 3}}$

\section{Artificial Neural Network Approach}

Artificial Neural Networks (ANN) is a computational nonlinear model that is commonly used in machine learning. It is effectively implemented to a wide spectrum of fields, and highly strong modelling techniques, particularly when the mathematical relationship of the specified data is unknown or not readily discerned [23]. Analogous to the brain framework, ANNs consist of single processing units called neurons. The neurons are structured in layers in the network framework as shown in Figure 5. Each of the neurons in the input layer gets one of the variables in which the values to rely on in the process of creating the predictive model. A neuron also has a bias that is regarded as an extra input to the neuron and a transfer function or activation defining the neuron type.

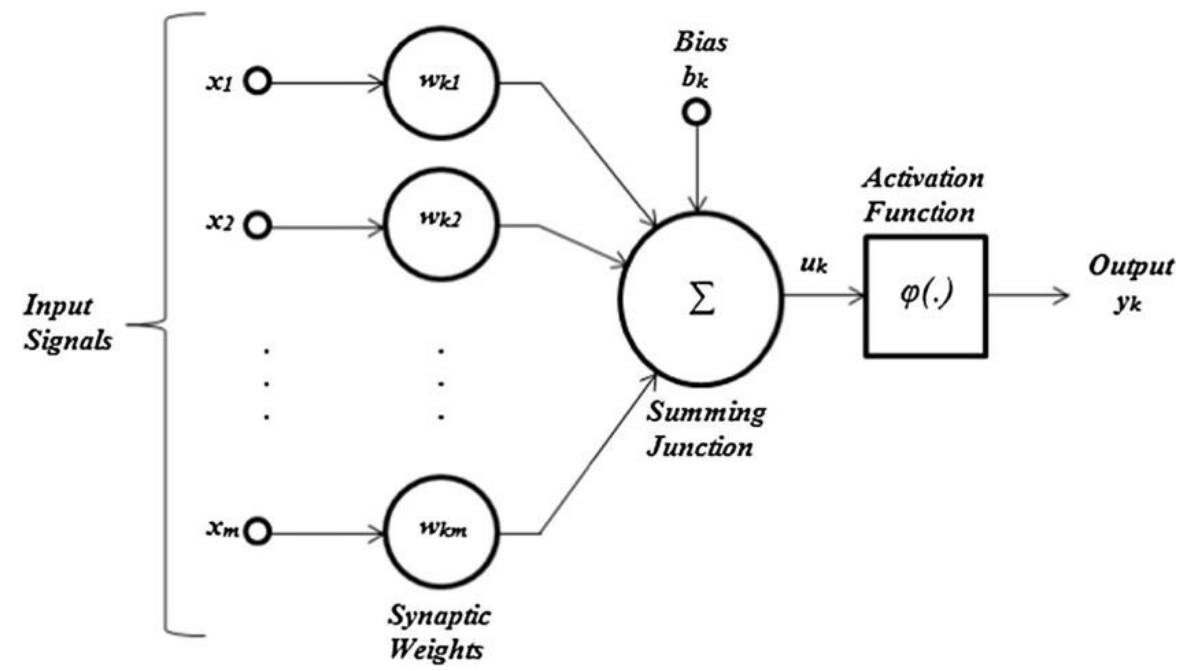

Fig. 5. Block diagram of model of a neuron [23]

Typically, the purpose of changing the weights is to offer the same performance as seen in the training data when learning an ANN with a set of input and output data. After the training step, the weights comprise significant information, whereas they are random and have no significance before training [24]. Furthermore, the aim of finding optimal weights is to achieve close target values as output [25]. In feedforward networks, backpropagation algorithms are broadly used as ANN learning algorithms. In this paper, the Levenberg-Marquardt learning algorithm selected for adjusting the weights in the feedback systems. The fundamental concept of the Levenberg-Marquardt algorithm is to perform a combination training: it transfers to the steepest descent algorithm around the complicated curve region until the local curve is appropriate for a quadratic estimate.

Accordingly, the ANN was created in this paper to evaluate the Nusselt number in the four flat tube bundles. Three input variables are used to estimate the Nusselt amount $(\mathrm{Nu})$ : Reynold number $(R e)$, tube angle $(\theta)$, and the heat flux $(q)$. The MATLAB software Neural Network toolbox was used for the ANN model implementation, the Figure 6 show the schematic representation of for the 
artificial neural network model. Neuron amount of hidden layer was determined by the trial and error. The data are randomly allocated to 70 percent, 15 percent and 15 percent respectively for training, testing and validation.
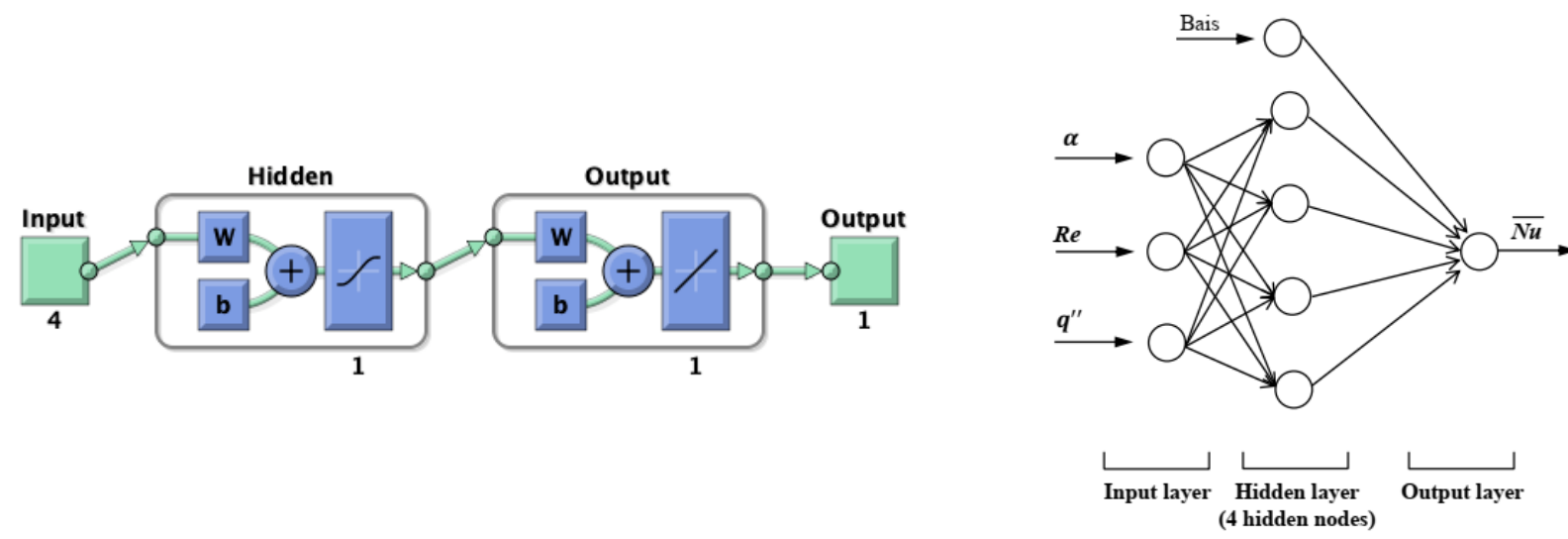

Fig. 6. Neural network architecture trained via Levenberg-Marquardt algorithm for the estimation of the Nusselt number

\section{Results and Discussion}

This section presents the experimental result of laminar forced convection heat transfer across four flat tube bundles with different attack angles. The main objective of the experimental part of this study is to conclude Reynolds number-Nusselt number relationship, Reynolds number-Coburn jfactor relationship and heat flux-Nusselt number Coburn $j$-factor and heat flux Colburn $j$-factor relationship. In addition, the discuss results of ANNs model.

Figure 7 shows the variations of mean Nusselt number $(\mathrm{Nu})$ with Reynolds number $(\mathrm{Re})$ for different heat flux supply and all air attack angles. It is clear that Nu number, increases with increase Re number. The heat flux except for the lowest value $\left(q^{\prime \prime}=13.2 \mathrm{~W} / \mathrm{m} 2\right)$ as shown in Figure $7(\mathrm{a})$. On the other hand, the Nu number, increases with increase $q^{\prime \prime}$ for all cases. In addition, the Nu decreases with increase air angles attack.

The variation Nu with total heat flux supply at different Re number was plotted in Figure 8 . The figure shows the Nu number decrease with increases angle attack. Figure clearly shows, increases $\mathrm{Nu}$ with increase $q^{\prime \prime}$ at all Re number, due to the temperature difference between the hot surface of the tube and air flow increases with Re increase also the time of contact of air flow and hot surface of tube, not enough and decrease with increase Re. The variation of Colburn j-factor values with Reynolds number values for several inlet air attack angles for flat tube are presented in Figure 9 . The resulting curve shows that $j$-factor decreases with an increase of Reynolds number for any heat flux supply or air attack angles. Colburn j-factor increases with the decrease of the air attack angles. This figure also presented the results of different heat flux supply. It could be noted that the heat transfer factor value is higher in low attack angles. 


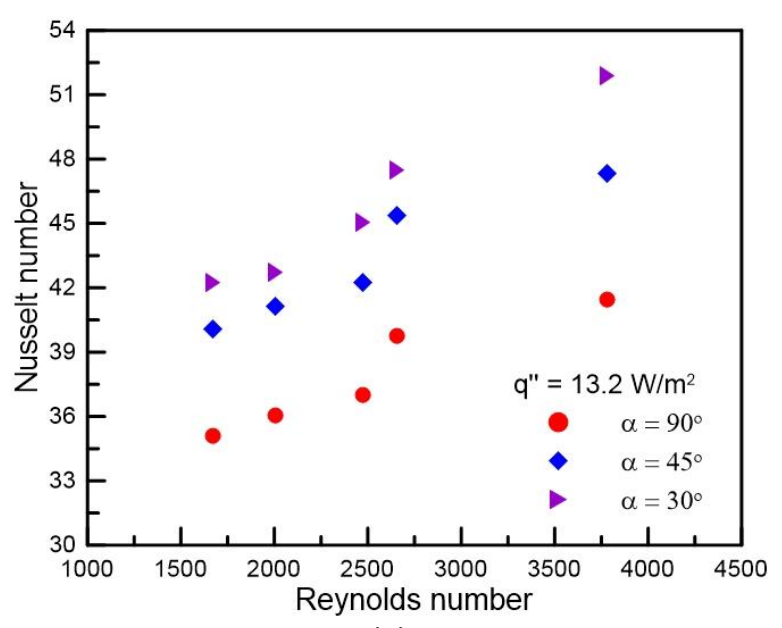

(a)

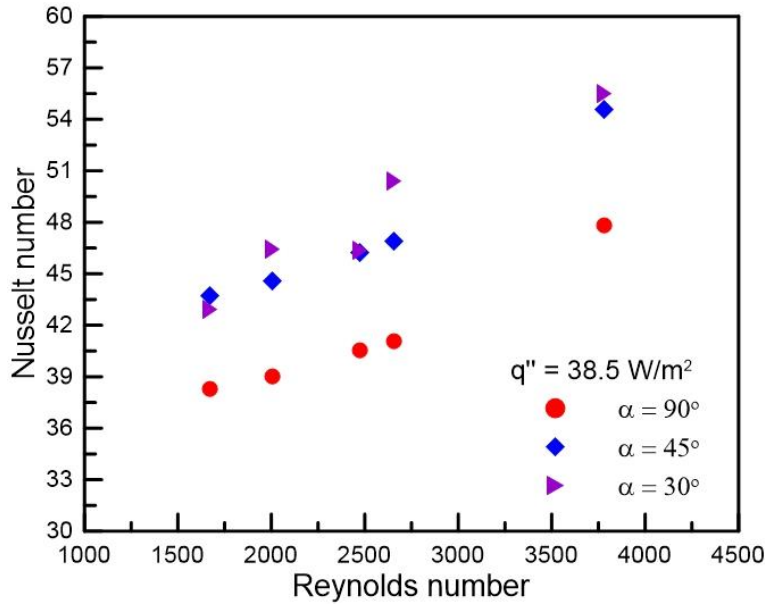

(b)

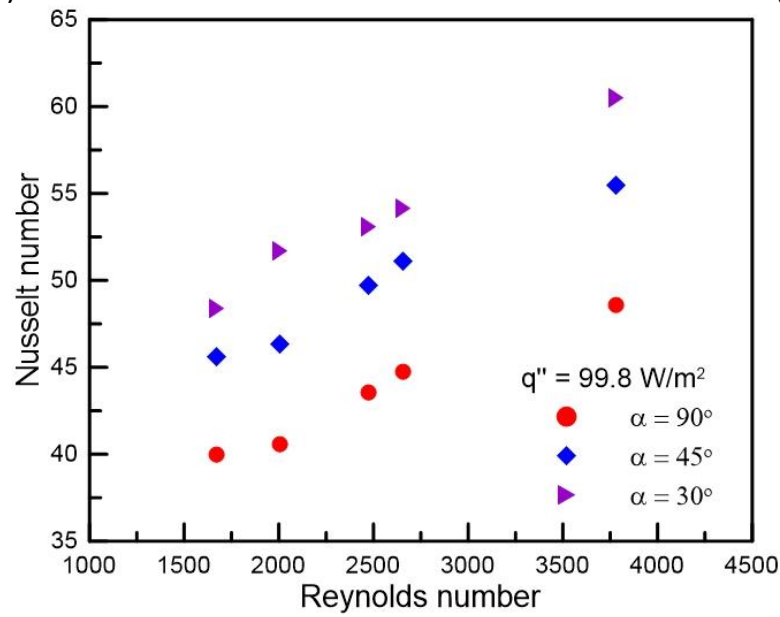

(c)

Fig. 7. The relationship between Reynolds number with Nusselt number for different heat flux with three air attack angles

For the predicted output, the relative error and the average relative error were performed by:

$$
\begin{aligned}
& R E \%=\frac{\left|X_{E x p t}-X_{\text {Pre }}\right|}{X_{\text {Expt }}} \times 100 \\
& M R E \%=\frac{1}{N} \sum_{i=q}^{N}(R E \%)_{i}
\end{aligned}
$$

where Expt, Pre, and $N$ are referring to mean experimental values, expected values, and experiment data, respectively. The determination ratio is used to quantify the degree of linear association between observed and predicted values. The general form for the coefficient of determination or $\left(R^{2}\right)$ equation is:

$R^{2} \equiv 1-\frac{S S_{r e s}}{S S_{\text {tot }}}$

where $S S_{\text {res }}$ is sum of squares of residuals, and $S S_{\text {tot }}$ is the total sum of squares. The ANNs model for training data and average Nusselt number shown in Figure 10. Where Figure 10 shows the compared between the experimental data with predicted date form ANNs model and Figure 11 shows the relative error between the real data (experimental) and predicted data. 


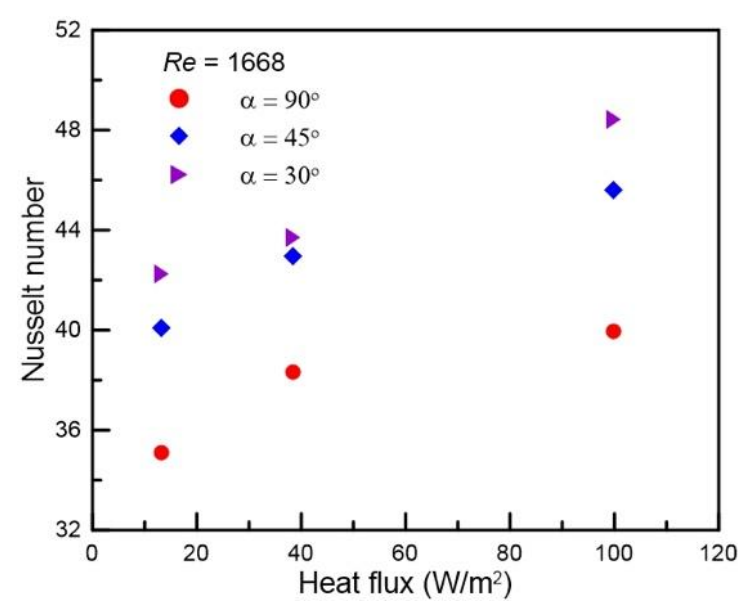

(a)

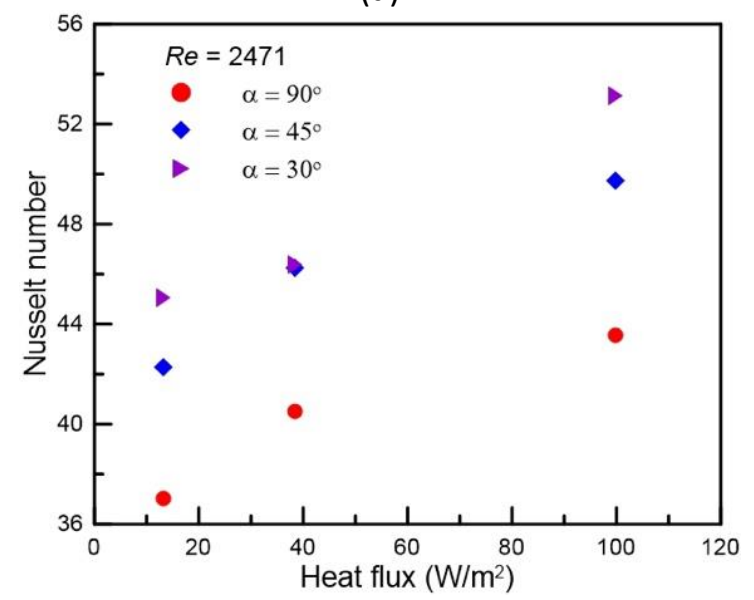

(c)

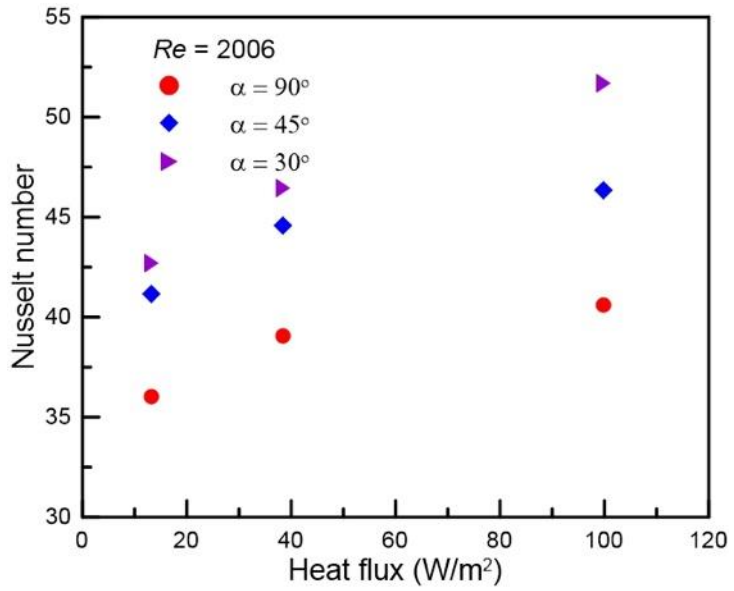

(b)

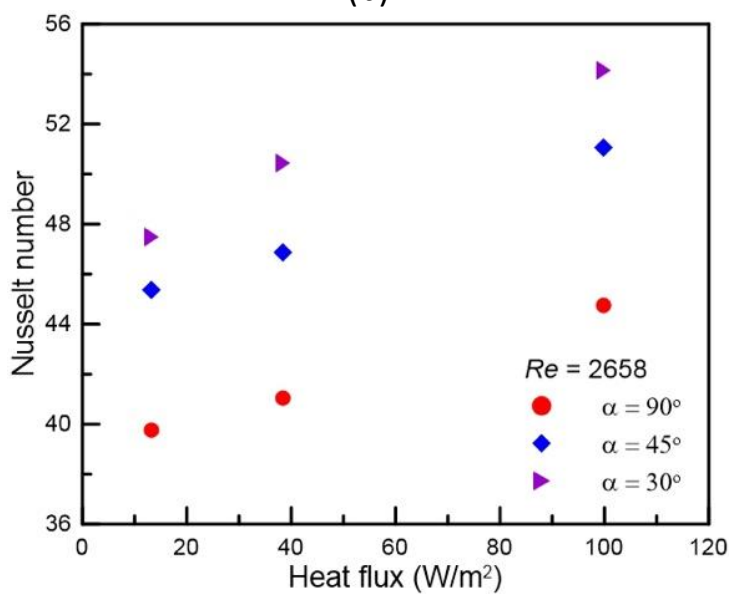

(d)

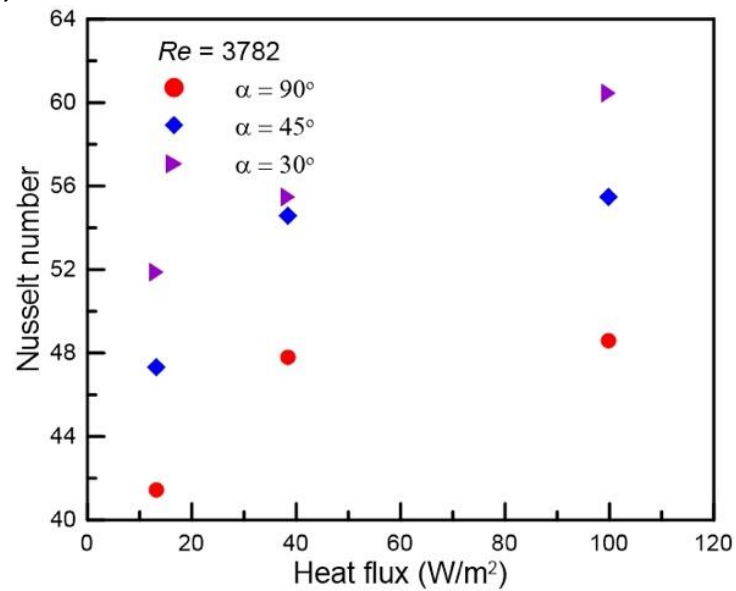

(e)

Fig. 8. The effect of heat flux on Nusselt number for diffident Reynolds number with all experimental cases 


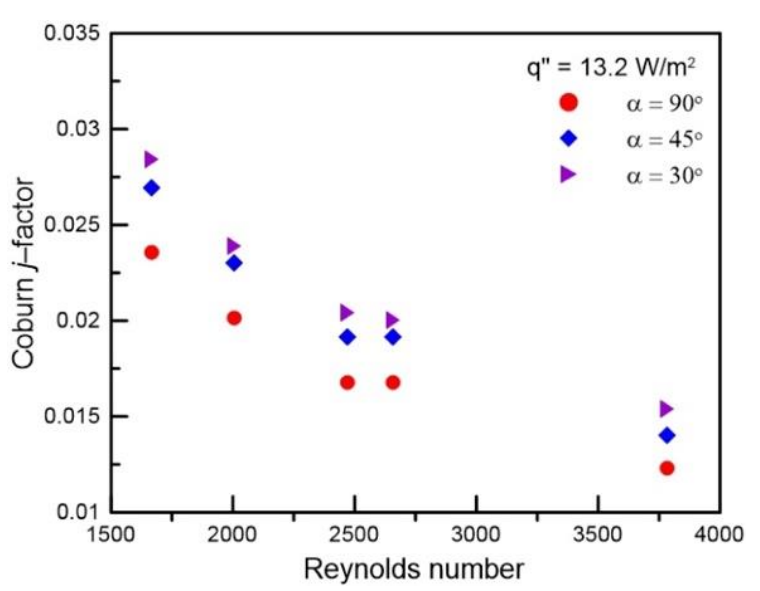

(a)

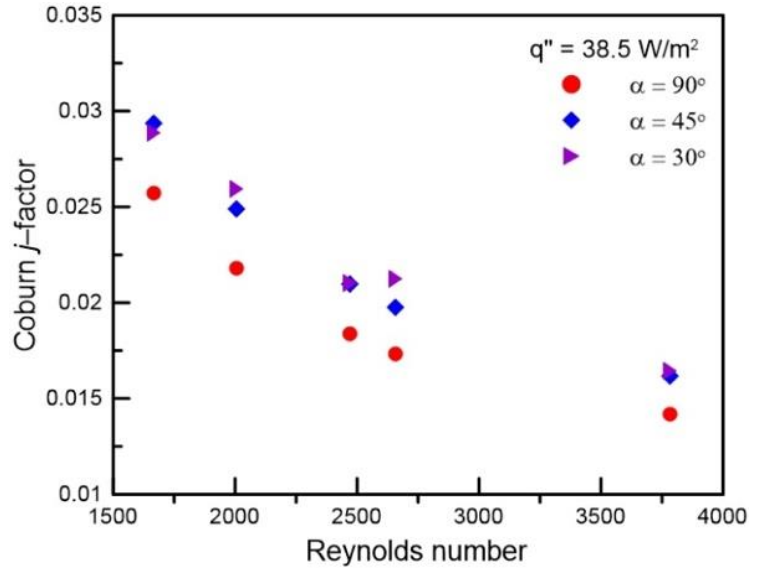

(b)

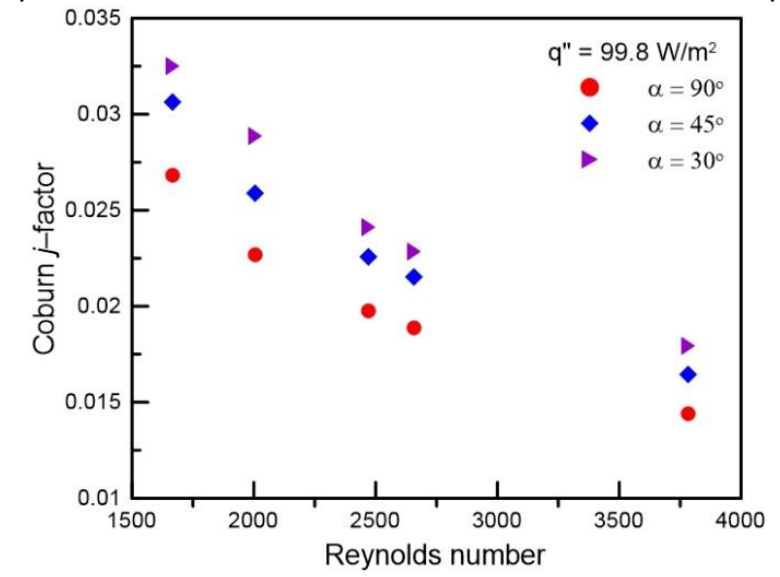

(c)

Fig. 9. Effect of Reynolds number on Coburn j-factor for all experimental cases

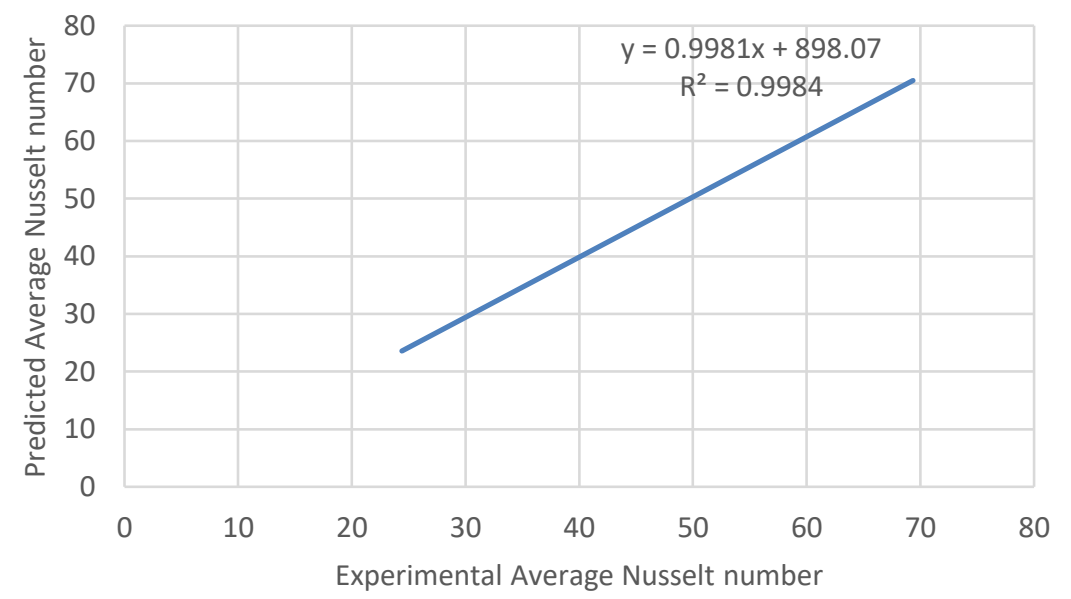

Fig. 10. Average Nusselt predictions and experimental by ANNs with training data 


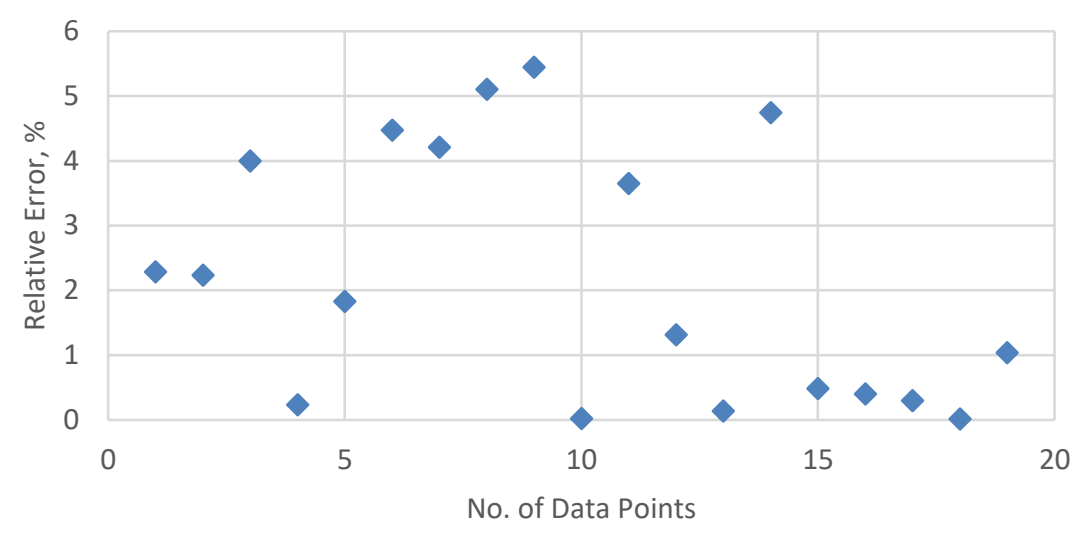

Fig. 11. The ANNs model's relative error in training data

\section{Conclusions}

This article involves the thorough experimental research experimental result of laminar forced convection heat transfer across four flat tube bundles. The second section created the ANN model using the estimation of the Nusselt number in this system. It has been shown that the ANN model is used efficiently to predict the heat transfer coefficient in airflow. The research findings for the training data: the mean relative error about $2.206 \%$ and the $R^{2}$ is $99.8 \%$. The ANN modeling can eventually be suggested to forecast the performance of heat transfer systems. Using ANN can prevent time-consuming and expensive experimental trials.

\section{Acknowledgements}

The researchers would like to express their deep gratitude to College of Engineering, University of Kirkuk for supporting this study. The second author expresses gratitude for the assistance of undergraduate student Lamia Emaad Khalaf and Tara Omar Salah.

\section{References}

[1] Bejan, Adrian, and Sylvie Lorente. Design with Constructal Theory. USA: John Wiley \& Sons, 2008. https://doi.org/10.1002/9780470432709

[2] Webb, Ralph L., and Nae-Hyun Kim. Principle of Enhanced Heat Transfer. Second ed. Taylor \& Francis, 1994.

[3] Wung, T. S., J. E. Niethammer, and Ching-Jen Chen. "Measurements of heat-mass transfer and pressure drop for some non-standard arrays of tubes in crossflow." In International Heat Transfer Conference Digital Library. Begel House Inc., 1986. https://doi.org/10.1615/IHTC8.480

[4] Eleiwi, Muhammad Asmail, Tahseen Ahmad Tahseen, and Ayad Fouad Hameed. "Numerical study of fluid flow and heat transfer in a backward facing step with three adiabatic circular cylinder." Journal of Advanced Research in Fluid Mechanics and Thermal Sciences 72, no. 1 (2020): 80-93.

https://doi.org/10.37934/arfmts.72.1.8093

[5] Nishiyama, Hideya, Terukazu Ota, and Tohru Matsuno. "Heat Transfer and Flow around Elliptic Cylinders in Tandem Arrangement." JSME International Journal. Ser. 2, Fluids Engineering, Heat Transfer, Power, Combustion, Thermophysical Properties 31, no. 3 (1988): 410-19. https://doi.org/10.1299/ismeb1988.31.3 410

[6] Rocha, L. A. O., F. E. M. Saboya, and J. V. C. Vargas. "A Comparative Study of Elliptical and Circular Sections in Oneand Two-Row Tubes and Plate Fin Heat Exchangers." International Journal of Heat and Fluid Flow 18, no. 2 (1997): 247-252. https://doi.org/10.1016/S0142-727X(96)00063-X

[7] Wang, Ye, Liang-Chen Wang, Zhi-Min Lin, Yu-Huan Yao, and Liang-Bi Wang. "The condition requiring conjugate numerical method in study of heat transfer characteristics of tube bank fin heat exchanger." International Journal of Heat and Mass Transfer 55, no. 9-10 (2012): 2353-2364. 
https://doi.org/10.1016/i.ijheatmasstransfer.2012.01.029

[8] Min, Jingchun, and Ralph L. Webb. "Numerical analyses of effects of tube shape on performance of a finned tube heat exchanger." Journal of Enhanced Heat Transfer 11, no. 1 (2004): 63-76.

https://doi.org/10.1615/JEnhHeatTransf.v11.11.50

[9] Ishak, M., Tahseen Ahmad Tahseen, and Md Mustafizur Rahman. "Experimental investigation on heat transfer and pressure drop characteristics of air flow over a staggered flat tube bank in crossflow." International Journal of Automotive and Mechanical Engineering 7 (2013): 900-911.

https://doi.org/10.15282/ijame.7.2012.7.0073

[10] Jassim, Ataalah Hussain, Tahseen Ahmad Tahseen, Ahmed Waheed Mustafa, Md Mustafizur Rahman, and Mahadzir Ishak. "An experimental investigation in forced convective heat transfer and friction factor of air flow over aligned round and flattened tube banks." Heat Transfer-Asian Research 48, no. 6 (2019): 2350-2369. https://doi.org/10.1002/hti.21496

[11] Tahseen, Tahseen A., M. Ishak, and M. M. Rahman. "Analysis of laminar forced convection of air for crossflow over two staggered flat tubes." International Journal of Automotive and Mechanical Engineering 6, no. 1 (2012): 755767.

https://doi.org/10.15282/ijame.6.2012.7.0061

[12] Tripathi, Brajesh, and Sandipan GhoshMoulic. "Numerical Evaluation of Inclined Ceiling Diffuser on Buoyancy and Airflow Patterns in an Enclosed Space." CFD Letters 3, no. 1 (2011): 48-64.

[13] Lin, T. Y., and C. H. Tseng. "Optimum design for artificial neural networks: an example in a bicycle derailleur system." Engineering Applications of Artificial Intelligence 13, no. 1 (2000): 3-14. https://doi.org/10.1016/S0952-1976(99)00045-7

[14] Genel, Kenan, Ibrahim Ozbek, Akif Kurt, and Cuma Bindal. "Boriding Response of AISI W1 Steel and Use of Artificial Neural Network for Prediction of Borided Layer Properties." Surface and Coatings Technology 160, no. 1 (2002): 38-43.

https://doi.org/10.1016/S0257-8972(02)00400-0

[15] Ermis, Kemal, Aytunc Erek, and Ibrahim Dincer. "Heat transfer analysis of phase change process in a finned-tube thermal energy storage system using artificial neural network." International Journal of Heat and Mass Transfer 50, no. 15-16 (2007): 3163-3175.

https://doi.org/10.1016/ji.ijheatmasstransfer.2006.12.017

[16] Fadare, D. A., and A. S. Fatona. "Artificial Neural Network Modeling of Heat Transfer in a Staggered Cross-Flow Tube Type Heat Exchanger." The Pacific Journal of Science and Technology 9, no. 2 (2008): 317-23.

[17] Islamoglu, Y., and A. Kurt. "Heat transfer analysis using ANNs with experimental data for air flowing in corrugated channels." International Journal of Heat and Mass Transfer 47, no. 6-7 (2004): 1361-1365. https://doi.org/10.1016/ji.ijheatmasstransfer.2003.07.031

[18] Tahseen, Tahseen Ahmad, M. Ishak, and M. M. Rahman. "Performance predictions of laminar heat transfer and pressure drop in an in-line flat tube bundle using an adaptive neuro-fuzzy inference system (ANFIS) model." International Communications in Heat and Mass Transfer 50 (2014): 85-97.

https://doi.org/10.1016/j.icheatmasstransfer.2013.11.007

[19] Rogers, Gordon Frederick Crichton, and Yon Richard Mayhew. Thermodynamic and Transport Properties of Fluids. 5th ed. UK: Blackwell Publishing, 2004.

[20] Naik, S., S. D. Probert, and M. J. Shilston. "Forced-convective steady-state heat transfers from shrouded vertical fin arrays, aligned parallel to an undisturbed air-stream." Applied Energy 26, no. 2 (1987): 137-158. https://doi.org/10.1016/0306-2619(87)90015-8

[21] Holman, J. P. Experimental Methods for Engineers. Eight ed. New York: McGraw-Hill, 2012.

[22] Nassif, Nabil, and Jordan Gooden. "Development and Validation of a Heat Pump System Model Using Artificial Neural Network." Advances in Science, Technology and Engineering Systems Journal 2, no. 3 (2017): 182-185. https://doi.org/10.25046/aj020323

[23] Tosun, Erdi, Kadir Aydin, and Mehmet Bilgili. "Comparison of Linear Regression and Artificial Neural Network Model of a Diesel Engine Fueled with Biodiesel-Alcohol Mixtures." Alexandria Engineering Journal 55, no. 4 (2016): 30813089.

https://doi.org/10.1016/j.aej.2016.08.011

[24] Gavin, Henri. "The Levenberg-Marquardt method for nonlinear least squares curve-fitting problems." Department of Civil and Environmental Engineering, Duke University (2011): 1-15.

[25] Bilgili, Mehmet, and Besir Sahin. "Comparative Analysis of Regression and Artificial Neural Network Models for Wind Speed Prediction." Meteorology and Atmospheric Physics 109, no. 1-2 (2010): 61-72. https://doi.org/10.1007/s00703-010-0093-9 